\title{
Topical Administration of Autologous Prothrombin at Sites of Bone Allografts Might be Helpful in Promoting Bone Healing after Bone Allograft Transplantation
}

\author{
Haibo Lu ${ }^{1,2,3}$, Shibi Lu ${ }^{3}$, Wenjing $\mathrm{Xu}^{3}$, Jiang Peng ${ }^{3}$, Aiyuan Wang ${ }^{3}$, Quanyi Guo*3, Yong Luo ${ }^{1}$, Chenyang $\mathrm{Nie}^{1}$ \\ and Sen $\mathrm{Li}^{1}$ \\ ${ }^{1}$ Department of Clinic Medicine, Hospital of People's Liberation Army Hong Kong Garrison, China \\ ${ }^{2}$ Department of Orthopaedics, First Affiliated Hospital of Chinese PLA General Hospital, China \\ ${ }^{3}$ Institute of Orthopedics of Chinese PLA, Chinese PLA General Hospital, China
}

Received: April 03, 2018; Published: April 12, 2018

*Corresponding author: Quanyi Guo, Institute of Orthopedics of Chinese PLA, Chinese PLA General Hospital, Beijing, China

\begin{abstract}
Most of prothrombin initially located within allograft bone matrix is removed or destroyed by deep-freezing, freeze-drying and gamma irradiation. Prothrombin is an inactive precursor to thrombin, a key factor which can promote bone healing. Therefore, we hypothesis that topical administration of autologous prothrombin at sites of bone allografts might be helpful in promoting bone healing after bone allograft transplantation and suggest appropriate amount of venous blood be harvested to concentrate autologous prothrombin before bone allograft transplantation.
\end{abstract}

Keywords: Prothrombin; Bone Allograft; Bone Healing; Deep-Freezing; Freeze-Drying; Gamma Irradiation

\section{Introduction}

Allograft bones are most commonly used materials for bone defects. Before being implanted, allograft bones are prepared by deep-freezing, freeze-drying and gamma irradiation to decrease the immunogenicity and the risk of disease transmission [1-3]. However, these methods can also get rid of or destroy most of osteoinductive proteins within the bone matrix. Therefore, these methods can compromise the bone healing of bone allografts and are related to unsatisfactory clinical outcomes. The incidence of fracture after implantation of large structural bone allografts was reported to be $5 \% \sim 20 \%$, and that of non-union, $10 \% \sim 15 \%$ [2]. We hypothesise that topical administration of autologous prothrombin at sites of bone allografts might be helpful in promoting bone healing after bone allograft transplantation. Prothrombin (PT, or coagulation factor II) is the coagulation factor present in the highest concentration in blood $(0.07 \mathrm{mg} / \mathrm{ml} \sim 0.1 \mathrm{mg} / \mathrm{ml})[4]$.

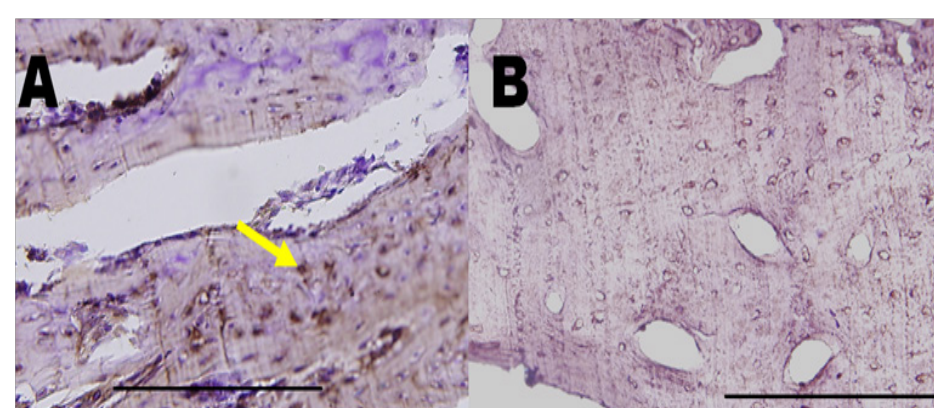

Figure 1: Most of prothrombin within the matrix of bones are removed and destroyed by freeze-drying and irradiation. A: fresh cortical bone of rat proximal femur; B: freeze-dried and irradiated cortical bone of rat proximal femur; yellow arrow, prothrombin. Immunohistochemistry stain; Bar length, $200 \mu \mathrm{m}$. 
It is an inactive precursor to the serine protease a-thrombin, a key factor which can not only trigger the cascade of coagulation, but also promote bone healing [5-7]. Conversion of PT to thrombin occurs in the prothrombinase complex, where PT together with coagulation factor Xa and factor Va are bound to negatively charged phospholipids on cell surfaces [8]. Recently, some researchers have found that prothrombin is synthesized and proteolytically processed in bone, and is present mainly in the newly formed bone matrix of metaphyseal trabecular bones [9]. Therefore, we consider prothrombin a helpful factor which might participate bone healing. And because most of prothrombin within the matrix of bones are removed and destroyed by freeze-drying and irradiation (Figure 1), topical supplement of prothrombin initially present within bone matrix might be helpful to promote bone healing of allograft bones. We suggest before bone allograft transplantation, 50 $\mathrm{ml} 100 \mathrm{ml}$ venous blood of the patient be harvested to concentrate autologous prothrombin by a safe and simple method [10]. Then the concentrated autologous prothrombin can be impregnated into bone allografts and implanted with bone allografts.

\section{References}

1. Williams A, Szabo RM (2004) Bone transplantation. Orthopedics 27(5): 488-495.

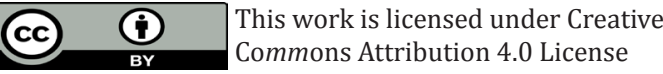

Submission Link: https://biomedres.us/submit-manuscript.php
2. McAuliffe JA (2003) Bone graft substitutes. J Hand Ther 16(2): 180-187.

3. Salai M, Vonsover A, Pritch M, von Versen R, Horoszowski H (1997) Human immunodeficiency virus (HIV) inactivation of banked bone by gamma irradiation. Ann Transplant 2(1): 55-56.

4. Mann KG (1976) Prothrombin. Methods Enzymol 45: 123-156.

5. Wang Y, Wan C, Szoke G, Ryaby JT, Li G (2008) Local injection of thrombinrelated peptide (TP508) in PPF/PLGA microparticles-enhanced bone formation during distraction osteogenesis. J Orthop Res 26(4): 539-546.

6. Amir LR, Li G, Schoenmaker T, Everts V, Bronckers AL (2007) Effect of thrombin peptide 508 (TP508) on bone healing during distraction osteogenesis in rabbit tibia. Cell Tissue Res 330(1): 35-44.

7. Pagel CN, de Niese MR, Abraham LA, Chinni C, Song SJ, et al. (2003) Inhibition of osteoblast apoptosis by thrombin. Bone 33(4): 733-743.

8. Norris LA (2003) Blood coagulation. Best Pract Res Clin Obstet Gynaecol 17(3): 369-383.

9. Karlstrom E, Norgard M, Hultenby K, Somogyi Ganss E, Sugars R, et al. (2011) Localization and expression of prothrombin in rodent osteoclasts and long bones. Calcif Tissue Int 88(3): 179-188.

10. Yi L, Minhu W, Juan D, Man C, Jiahui D, et al. (2009) Comparative Analysis of Two Extraction Methods of Prothrombin. J Chengdu Med College 4: 46-48.

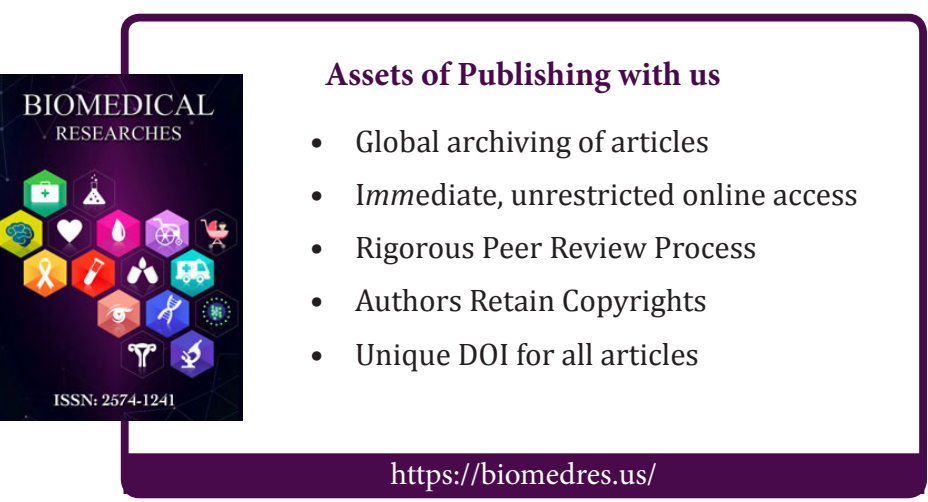

